\title{
Cristianismo contemporâneo: desafios interconfessionais e interculturais
}

\section{Editorial}

\author{
ELIAS WOLFF (DDa
}

WALDIR SOUZA (iDb

O pensar teológico caracteriza-se como exercício de articulação sistemática das "razões da fé" (1Pe 3,15), respondendo às interpelações dos diversos contextos socioculturais e religiosos, e apresentando a fé como o horizonte de sentido que situa a pessoa crente nesses contextos. A teologia desenvolve-se, assim, como uma via de mão dupla: da realidade para a fé e da fé para a realidade. Busca apreender intelectualmente elementos que, não obstante a sua natureza mistérica, exigem uma racionalidade crítica. Assim é a fala sobre Deus, revelação, graça, igreja, sacramentos, escrituras sagradas, entre outros. Somente estudados com criticidade tais temas têm plausibilidade de sentido e de acolhida em diversas instâncias e ambientes, religiosos e para além deles.

Em nossos tempos, a teologia assume novas pautas, formadas por questões candentes do mundo marcado pela internacionalização, globalização e tecnologia, como a ecologia, a tecnociência, a bioeticidade, a interculturalidade, o pluralismo religioso e eclesial, questões de gênero, as mídias eletrônicas e digitais, entre outras. Não são apenas temas teológicos, mas uma "nova problemática teológica" (BOFF, 1998, p. 51) que exige nova

a Pontíficia Universidade Católica do Paraná (PUCPR), Curitiba, PR, Brasil. Doutor em Teologia, email: elias.wolff@pucpr.br

b Pontíficia Universidade Católica do Paraná (PUCPR), Curitiba, PR, Brasil. Doutor em Teologia, email: waldir.souza@pucpr.br 
sistematização do saber da fé. Emergem, então, as teologias contemporâneas, como as teologias étnicas, teologia política, teologia da libertação, teologia ecumênica, teologia das religiões, teologia pública, teologia de gênero etc. Só existem teologias contemporâneas porque a fé cristã se confronta e dialoga com o mundo contemporâneo. Elas expressam o compromisso do/a teólogo/a com o mundo no qual vivemos. $\mathrm{E}$ isso torna-se ainda mais significativo neste momento em que praticamente a humanidade inteira sofre a pandemia do novo coronavírus. A situação pandêmica mergulha a existência humana em situações limites nas quais se acentuam questões cruciais sobre o sentido, comprometendo a teologia na busca por respostas. E desse modo o pensar teológico é um serviço à igreja que "caminha juntamente com a humanidade, participa da mesma sorte terrena do mundo" (GS 40).

Isso não significa que a teologia deixa de pensar temas considerados clássicos ou nucleares como a cristologia, a graça, a escatologia, a eclesiologia, ou que já resolveu todos os problemas que esses temas comportam. Exatamente porque "clássicos", esses assuntos não são démodé. "Revelação", "Ressurreição", "Salvação", "Reino" compõem o "princípio arquitetônico" (MONDIN, 1983, p. 8-11) da teologia. Mas eles recebem novos enfoques, com novas articulações dos dados originários da fé em relação às novas situações da humanidade. E a teologia não precisa temer ficar sem interlocutores nos areópagos do nosso tempo, pois questões religiosas, até pouco tempo exclusivas da teologia, são abordadas hoje por outras ciências, notoriamente as Ciências da Religião, a Filosofia, a Psicologia, a Antropologia, a História, entre outras. Isso contribui para o avançar do pensar teológico, reconsiderando as soluções dadas aos problemas de ontem e atenta às formas como eles ressurgem hoje, além de assumir as novas questões emergentes.

Aqui estão em jogo tanto questões de conteúdo quanto de método do labor teológico. A organização interna do saber teológico está sempre vinculada às suas condições de produção. A atual "mudança epocal” exige rever o constructo epistêmico da fé cristã, considerando que as transformações não acontecem apenas em detalhes da cultura ou da fé, mas no marco total de referências. Trata-se de uma "mudança de paradigmas" (KUHN, 1962, p. 219) que exige remodelação em toda a estrutura do sistema teológico, com uma virada hermenêutica que mostra "um cristianismo sob o 
risco da interpretação" (GEFFRÉ, 1983). Nessa remodelação, a teologia se propõe como interpretação criativa dos dados de fé, se desenvolve como razão aberta e numa correlação crítica e mútua entre passado e presente, doutrina e experiência, religião e sociedade. Explicita a pertinência do mistério cristão ao mundo atual no horizonte da interculturalidade, interdisciplinaridade, intergeracionalidade, interconfessionalidade, como elementos constituintes da episteme da fé.

Isso significa que teologia se faz como e no diálogo, cujas conclusões precisam ser mutuamente acessíveis e comumente tecidas. A proposta do diálogo não é apenas um leitmotiv mas um paradigma que redimensiona o pensar da fé, com implicações no modus essendi et operandi das comunidades de fé. No diálogo, o saber da fé acontece por uma "fusão de horizontes" (GADAMER, 1997, p. 457), reconstruindo hermenêuticas de ontem e de hoje sobre Deus, sagrado, religião. Assume-se que o universo semântico de todo conceito ou princípio teológico-doutrinal tem uma construção histórica. Porém, mais que o conceito (Revelação, Ressurreição, Salvação), importa à teologia garantir hoje a sua "intencionalidade". O princípio hermenêutico possibilita uma espécie de apropriação da "realidade" que essas categorias expressam, sem enclausurar o Mistério que pode ser dito por categorias e formas linguísticas outras, mantendo o conteúdo da tradição cristã - num arriscado paralelo entre "tradição", "tradução" e "traição", de comum origem etimológica. É o caráter noético e dinâmico da tradição de fé o que exige que as pautas clássicas da discussão teológica sejam revistas em sintonia com as pautas emergentes, numa relação de inter-saberes e interconfessionalidades, iluminando vivências em novas referências culturais.

Concretizando e exemplificando a reflexão, as pesquisas nas diversas áreas sociais impulsionaram a Teologia do Evangelho Social (Rauschenbush), a Teologia do Processo (Whitehead), a Teologia da Cultura (Tillich), a Teologia Política (Metz), a Teologia da Libertação (Gutiérrez) e mais recentemente emergem as Teologias de Gênero, Teologia Pública e Decolonial, entre outras. As questões ecológicas permitem refazer a Teologia da Criação, promovendo o cuidado pela Casa Comum onde "tudo está interligado" (FRANCISCO, 2015, n. 91); a antropologia favorece o redimensionamento da Teologia da Graça, afirmando Deus na intimidade de toda realidade, o que supera a concepção 
extrincesista do seu agir e o deísmo intervencionista; as ciências das religiões possibilitam "repensar a Revelação" (QUEIRUGA, 2010), a Soteriologia, a Espiritualidade/Mística, a Pneumatologia, acolhendo a positividade do pluralismo de credos, base da Teologia das Religiões (Jacques Dupuis, Paul Knitter, John Hick); a filosofia da história ajuda a repensar a Escatologia, afirmando a esperança na plenitude final de tudo se dá no processo de desenvolvimento da realidade (Moltmann, Balthasar, Pannemberg); estudos de semiótica sobre os símbolos e signos, a fenomenologia e o existencialismo, contribuem para o redimensionamento da Teologia dos Sacramentos, numa perspectiva existencial, intercultural e ecumênica (Osborne, Borobio, Chauvet).

Enfim, fazer teologia é mostrar que "a fé dá o que pensar" no encontro com as realidades humanas e a criação como um todo. E tantas são as teologias quanto são as hermenêuticas e os métodos utilizados para refletir elementos da fé em relação com as questões do mundo. Isso significa que um/a teólogo/a não entende apenas de teologia. Mesmo que não domine outras perspectivas do saber precisa, ao menos, identificar suas implicações e pressupostos para a reconstrução do universo semântico das categorias e formulações teológicas. Com isso a teologia não se arvora ocupar o lugar da sociologia, antropologia, história, mas dialogando com elas sente-se enriquecida pelas suas pesquisas para a manutenção da sua especificidade, do que destacamos:

1) A teologia trabalha com o sentido último, transcendental, das vicissitudes do/no cotidiano existencial. Mesmo se tratadas também por outras ciências, há na lógica epistêmica destas um horizonte de imanência insuperável. Por isso nem todo falar de Deus, fé, sagrado, espiritualidade, religião, ou sentido existencial é teologia. Sem confundir linguagens, métodos e especificidades na abordagem, sem trair a semântica de fé dos conceitos, o pensar teológico tem estatuto próprio, não se confunde com outras ciências quer seja tratando de questões emergentes na atualidade, quer investigando questões permanentemente presentes no constructo pístico da fé cristã. A transcendência teológica está na inteiligentia fidei, ou numa fé inteligente, que identifica na experiência humana o sentido profundo de situações e realidades de significativa complexidade, como vida, sofrimento, norte, pobreza, injustiça, violência, paz, entre outras. São nas situações deste mundo que, ao 
serem teologizadas, colhe-se a questão sobre Deus, salvação, espiritualidade, não como especulação acadêmica simplesmente, mas no horizonte mistagógico, como exercício contemplativo da fé que deseja saber.

2) Nada do que diz respeito ao mundo é alheio ao pensar teológico. Como consequência, o vínculo com a realidade é constitutivo do estatuto teológico que sustenta a inteligência da fé em torno de temas contemporâneos. $O$ ato teológico é feito como engajamento no mundo, como ensina a tradição teológica latino-americana: a teologia tem uma "verdade encarnada" (SEGUNDO, 1991, p. 207). Karl Barth já havia afirmado, na Carta aos Romanos, que teologia se faz com a bíblia em uma mão e o jornal na outra. Assim, o primeiro interlocutor do/a teólogo/a é a realidade, não é outro/a teólogo/a ou cientista. O pensamento que é fruto de outro pensamento e que se desenvolve encerrado apenas em bibliotecas é inócuo. Bem ensina o Papa Francisco: "A realidade é mais importante do que a ideia" (2014, n. 231-233). Portanto, "ver/conhecer/analisar" teologicamente a realidade implica numa atitude existencial com opções compromissivas. Nesse sentido, urge superar um déficit de engajamento vivencial para o pensar teológico em nossos dias. $\mathrm{E}$ isso se faz teologizando não apenas "sobre" ou "a partir da" realidade, mas na realidade. A pístis teológica é, primeiramente experiência, como fides qua. Teologizar implica em proximidade/vivência concreta na realidade teologizada. Pois o primeiro ato do/a teólogo/a é ouvir a realidade, deixá-la falar. A teologia faz-se como mediação ou facilitação da fala da realidade, no processo maiêutico proposto por Andrés T. Queiruga. Esse é o momento do intellectus fidei, da interpretação do que se ouve na realidade, como hermenêutica dos "sinais dos tempos" (GS n. 4; DAp n. 33). Agora a teologia emite sua voz, fala "da" e "a partir" da realidade onde está. E sempre em diálogo com outras vozes, pelo que o pensar/falar teológico se constrói na com-paixão, no com-panheirismo, na com-unidade. Afinal, a realidade sociocultural e religiosa que interpela a fé e instiga à reflexão precisa antes da nossa presença, como teólogos/as, do que das nossas ideias.

3) Para falar com plausibilidade de ser ouvida na cultura atual, a(s) teologia(s) afirma(m) a sua cidadania acadêmica como conhecimento sistematizado com os critérios do pensar científico e domínio na área de conhecimento. Como saber sistêmico, ela tem objeto, objetivos, métodos e 
horizontes hermenêuticos próprios. Isso assegura à teologia a capacidade e competência argumentativa acerca do que investiga, bem como a aplicabilidade do seu saber aos diversos problemas científicos e práticos da humanidade. Contudo, Deus não é objeto de conhecimento igual aos objetos de outras ciências. O Mistério não pode ser demonstrado por métodos empíricos ou por discursos científicos. É com humildade que a teologia, mesmo acadêmica, demonstra que o Deus absconditus pode ser "apreendido" pelo intellectus fidei, embora não seja "compreendido" pela ratio (mesmo teológica), como ensina a teologia apofática. Em termos clássicos, ao auditus fidei segue o intellectus fidei, e apenas em terceiro momento vem a ratio fidei, como articulação sistemática e acadêmica do apreendido pela intelligentia da fé.

4) Nisso a teologia se constitui como serviço à razão da fé eclesial e mantém uma função apologética, no sentido etimológico do termo: justificar a fé das comunidades no mundo atual. Ela o faz orientando as relações das comunidades com o mundo e iluminando as questões do mundo para as comunidades. É uma dupla inserção, num estreito vínculo entre sociedade e eclesialidade, cultura e missionariedade, militância e espiritualidade, confessionalidade e ecumenicidade. A teologia ajuda a igreja a "entrar com fé" no debate das questões do mundo, como serviço concreto ao mundo e às comunidades de fé, simultaneamente. A questão a ser respondida é: "que igreja para o mundo atual"? A pergunta concreta não se satisfaz com respostas abstratas, ainda que bem elaboradas. A superação do déficit de realidade, acima dito, diz respeito à necessidade de superar também certo déficit de chão eclesial em teologias do nosso tempo. Se não é possível teologizar fora da vivência concreta, somente uma teologia eclesialmente comprometida ajuda a igreja a afirmar a autenticidade original da fé cristã no mundo atual, sem reduzir-se a conveniências, rituais vazios ou um código de normas. Teologia é, então, sentire cum ecclesia e sentire cum mundo, simultaneamente, os desafios que hoje implicam na missão, na concepção das estruturas eclesiais, o lugar e o papel da mulher nessas estruturas, a corresponsabilidade entre clero e laicato, a questão do poder e da autoridade, a interconfessionalidade doutrinal, entre outros. Somente uma teologia eclesialmente comprometida presta esse serviço de forma competente, numa coerência entre os 
pressupostos de fé e os resultados da investigação acadêmica sobre a fé, o que garante às pesquisas teológicas contribuir para as reformas e as atualizações de que a igreja do nosso tempo tanto necessita.

5) Teologia em tempos de pós-modernidade e pós-verdade se faz sem alguma concepção do divino? Desde que Max Weber, Marcel Gauchet e Charles Taylor começaram a afirmar o "desencantamento do mundo", mudou-se a relação entre fé e religião, com implicações para a relação fé-teologia. Emergem a Teologia da Secularização (Bonhoefer), a Teologia da Morte de Deus (Thomas Altizer, Paul van Buren, William Hamilton), a Teologia do Cristianismo sem Religião (Marcel Gauchet; Gianni Vattimo). Na sociedade secularizada, muitas pessoas, com sede de fé, abandonaram os sistemas religiosos, desencantados das doutrinas e estruturas da própria fé. O desejo religioso, como fato antropológico, é considerado suficiente para expressar o desejo implícito de Deus. E entendendo evitar um cristianismo deformado, há quem opte por percorrer um caminho diferente da igreja ou mesmo sem ela. Por isso Gauchet afirma "o religioso após a religião" e, mesmo se observa nas teologias contemporâneas uma herança cristã, entende que isso tem deixado de ser necessário. Desse modo, uma teologia secular, acadêmica e científica pode ser desenvolvida por agnósticos ou ateus, traçando o desenvolvimento das crenças na história atual.

Tal fato questiona as formas tradicionais do pensar teológico, que enclausura Deus em doutrinas, ritos e normas. Numa cultura de pósmodernidade e pós-verdade, a teologia como "razão aberta" precisa colher as contribuições dessa cultura para repensar seu universo dogmático. As suas narrativas deixam de ser metafísicas, essencialistas, e se constroem como intra-físicas ou intra-históricas. E como aí não há saber totalizante, há muitas formas de pronunciar "o Nome” de Deus. Na perspectiva cristã, já não é suficiente à teologia afirmar Deus, é preciso mostrar "qual Deus" afirma. É o Deus de Jesus Cristo, o Deus do Reino da "vida em abundância" (Jo 10,10) para toda criatura, amoroso, misericordioso e compassivo. Essa concepção do divino dialoga fecundamente com outras concepções da Realidade Última no pluralismo religioso e cultural. As diferentes concepções do divino, teologicamente afirmadas, prestam um importante serviço às comunidades religiosas, sustentando ações e utopias que qualificam a existência. Por isso, é 
importante perguntar a quem serve uma teologia sem Deus, se para intelectuais e a academia, ou às comunidades que buscam entender o sentido do Nome de Deus em suas vicissitudes cotidianas.

Não se trata de elaborar uma teologia cartesiana, com "ideias claras e distintas" do seu objeto. Sempre existe uma hibridização hermenêutica, com o auxílio das ciências no entendimento da fé contextualmente situada. O que dizemos é que mais que o objeto material (que pode ser comum a outras ciências), é o objeto formal (fé in-formada pela Revelação) que caracteriza a teologicidade do pensar. Então tem sentido afirmar a teologia como o entender "a partir de Deus" as diversas realidades investigadas. Uma afirmação teológica que prescinde de Deus é tão vulnerável quanto uma afirmação sobre Deus que prescinde da teologia. A primeira é vazia de fé/sentido para a realidade da/na qual fala; e a segunda é vazia de realidade para a fé/sentido.

Isso tudo mostra que o ato de professar a fé e de pensar a fé se dá sempre em situações históricas concretas. Não mais se admite uma compreensão ingênua da fé, nem que essa se afirme com posturas de uma apologética conflitiva. Contribuindo para uma teologia atualizada e dialógica, o Dossiê v. 12, n. 3, 2020 da Pistis \& Práxis propõe análises do Cristianismo contemporâneo: desafios interconfessionais e interculturais, com excelentes artigos que formam o Dossiê e a seção Fluxo Contínuo. No Dossiê, temos:

Afonso Murad reflete sobre "Ecoteologia: uma reflexão contemporânea para os tempos atuais". O autor entende que "A consciência ecológica se tornou um diferencial na contemporaneidade". Uma vez que "o ser humano é membro da Terra", é também responsável pela Casa Comum de todos os seres que nela vivem. Isso tem a ver com a teologia, que reflete sobre a vida "não simplesmente como um tema da moral ou da dogmática (teologia da criação), e sim como uma nova perspectiva de pensar a fé, viver a espiritualidade e atuar no mundo".

Stefano Raschietti analisa "Puebla e a missão além-fronteiras", apontando pistas para superar uma concepção de missão eclesiocêntrica "que impede uma autêntica saída rumo ao encontro com os outros". Reflete, particularmente, sobre "uma evangelização mais encarnada junto aos povos indígenas" como amadurecimento da missão, bem como a tentativa de 
"compor um quadro orgânico e global das situações missionárias no mundo de hoje".

Claudio de Oliveira Ribeiro contribui para ampliar horizontes teológicos propondo "O princípio pluralista diante das dimensões do lúdico e da festividade". O autor destaca aspectos de novas linguagens teológicas presentes nos desejos humanos, com dimensões lúdicas e místicas do viver marcado pela festividade, alteridade, diferença, poesia, fragilidade e empoderamento. Valoriza, assim, as teologias narrativas e a teopoética como "visões de recriação da linguagem teológica", com elementos simbólicos e de forte apelo existencial que traduzem concepções teológicas fundamentais da fé.

Ainda sobre o pluralismo religioso, o artigo de Luiz José Dietrich, Nadi Maria de Almeida, Victor Dunne, Roseane Almeida da Silva e Maria Antônia Marques apresenta significativa pesquisa sobre "Pluralismo religioso e estudo crítico da Bíblia: desafios à missão, ao diálogo inter-religioso e às teologias cristãs africanas". Apontam o pluralismo religioso como lugar da reflexão teológica atual, no contexto da teologia das religiões e intuições do Vaticano II, contextualizando a reflexão nas peculiaridades, avanços e barreiras das teologias cristãs africanas em diálogo. Incentivo particular é dado ao diálogo entre teólogos/as e biblistas sobre a compreensão do processo de instituição do monoteísmo em Israel e no Cristianismo, no processo de constituição das teologias dentro da Bíblia e também das doutrinas, teologias e dogmas no período pós-bíblico e ao longo da cristandade. Entendem que, "assim, nos reaproximaremos de Jesus de Nazaré, que testemunhou sobre o Mistério Maior, ensinando a buscá-lo, encontrá-lo e a experimentá-lo em todas as conjugações e em todas as potências do verbo amar, fazendo-o crescer em todas as culturas e em todas as religiões, a começar pela nossa".

Graham Gerald McGeoch reflete sobre "Cristianismo contemporâneo Desafio interconfessional e intercultural. O ministro paroquial e o pluralismo religioso". O autor aborda a experiência de pároco na Igreja da Escócia ciente dos desafios que o pluralismo religioso the apresenta. Lê teologicamente a própria experiência de diálogo sobretudo com o judaísmo e o islamismo. A novidade está no incentivo para iniciativas litúrgicas comuns, com um rico intercâmbio de púlpito entre as comunidades cristãs, judaicas e islâmicas. 
Lubomir Zak e Marcio Luiz Fernandes continuam o estudo interconfessional afirmando que "Não há interconfessionalidade sem uma reforma da Igreja: uma reflexão à luz da recepção intra-católica dos resultados do diálogo católico-luterano". Os autores entendem “que uma autêntica e fecunda interconfessionalidade não pode ser realizada sem uma corajosa reforma da Igreja e, por conseguinte, do cristianismo como um todo". Concentram a reflexão no diálogo católico-luterano, analisando como a celebração do V centenário da reforma de Martinho Lutero expressou importante "grau de maturidade ecumênica da Igreja católica na sua capacidade de interpretar os eventos em torno da Reforma luterana”. A partir daí, incentivam o catolicismo para rever suas narrativas históricas e teológicas de modo a favorecer a experiência de interconfessionalidade.

Ainda na perspectiva ecumênica, Elias Wolff propõe "Elementos para uma teologia ecumênica dos sacramentos". Analisa como as vivências sacramentais no interior do pluralismo eclesial possibilitam uma reconstrução epistemológica da teologia sacramental, em perspectiva ecumênica, com implicações em seu método e na hermenêutica dos sinais sacramentais da fé cristã. Para isso, insere a teologia sacramental em elementos da atual cultura, dialogando com a fenomenologia e o existencialismo, que oferecem possibilidades para uma nova compreensão e vivência das experiências sacramentais.

Em diálogo com a cultura secularizada, Paulo Sérgio Lopes Gonçalves analisa a "Religião débil da caridade. O cristianismo não religioso em debate". O autor analisa a proposta do cristianismo centrado na caridade e solidariedade, com o sonho de que os povos vivam a fraternidade, a justiça e a paz, tal como proposto por Gianni Vattimo em diálogo com Richard Rorty e John Caputo. Numa pesquisa histórica, filosófica e teológica, busca "mostrar a debilidade do cristianismo ao se concentrar na caridade, no seu caráter emancipador e na força de promover a fraternidade, a solidariedade e a paz".

Marcial Maçaneiro e Cirlene Cristina de Sousa refletem sobre "A Igreja e o Povo Judeu: do antissemitismo ao reconhecimento". Tratam das "relações entre a Igreja Católica e o povo judeu com duas chaves de análise: o antissemitismo como questão moderna e como fato teológico". Examinam os fatores modernos do sentimento antijudaico, entendendo o Holocausto como 
a materialização político-ideológica do ódio aos judeus, caracterizado como antissemitismo moderno. Examinam também as raízes cristãs do antissemitismo, que remontam às controvérsias hebraico-cristãs dos séculos III-IV d.C.. Num terceiro momento, o artigo mostra como o Vaticano II propõe uma guinada nas relações entre católicos e judeus, condenando o antissemitismo e reconhecendo as raízes judaicas do Cristianismo. As duas tradições religiosas têm hoje um percurso comum para percorrer, "com passos de verdade, justiça e paz".

Ziad Fahed e Marie Belle Saliba refletem em seu artigo sobre "Como os meios de comunicação social podem ser usados para promoverem a Doutrina Social Católica: um estudo de caso libanês. Ensino Social Católico". Analisam o grande uso atual das mídias eletrônicas e digitais, aplicativos e outros recursos de comunicação que conectam pessoas, povos e culturas. Constatam que há importantes estudos sobre como esse fato afeta a igreja, mas não como favorecem o seu ensino social, e buscam superar essa lacuna mostrando como a mídia pode favorecer ao ensino católico sobre paz, justiça e dignidade humana, tendo o Líbano como um caso específico.

Em seguida, temos o artigo de Edelcio Serafim Ottaviani sobre "Profetismo e resistência ao poder clerical num movimento feminino do séc. XII: luzes para o papel eclesial da mulher em tempo de pós-pandemia". O autor reflete sobre a ação pastoral da Igreja pós-pandemia, analisa as crises sociais e eclesiais no contexto pandêmico e problematiza a ênfase dada à celebração eucarística virtual, como "médium de uma pastoral de manutenção, por meio da qual mais uma vez é obnubilado o papel evangelizador das mulheres". Com José Comblin e Michel Foucault, Ottaviani se reporta ao movimento das beguinas do séc. XIII, mostrando o clericalismo patriarcal nas estruturas eclesiais e, de volta ao nosso tempo, apresenta as discussões ocorridas no Sínodo da Amazônia "como forma de instauração de um discipulado de iguais, capaz de interceptar o colonialismo e o patriarcalismo", na igreja e no mundo. Conclui o Dossiê o precioso artigo de Helmut Renders, "Razão e afeto nos Pia Desideria: inspiração para uma linguagem interconfessional contemporânea". O autor mostra que "interconfessionalidade e interculturalidade se (des)articulam por linguagens textuais, metafóricas e visuais compartilhadas, mediante hibridizações, mestiçagens, resgates, 
aniquilações e inversões". Por essa razão "o dia-logo da inter-relacionalidade requer, uma linguagem, no mínimo, parcialmente compatível, mutuamente acessível ou até comumente tecida". O artigo explora o significado original da metáfora pia desideria no católico Herman Hugo (1624) de Bruxelas, no pietista luterano Philipp Jacob Spener (1675) de Frankfurt e no puritano Cotton Mather (1722) da América do Norte, identificando neles "um tipo indireto de interconfessionalidade", mostrando que a metáfora dos pia desideria pode servir como exemplo de uma linguagem religiosa capaz de sustentar e promover debates interconfessionais.

Na seção Fluxo Contínuo, José Aguiar Nobre escreve sobre "Espírito Santo e Missão: algumas reflexões à luz da teologia da revelação de Andrés Torres Queiruga". O autor busca "haurir as inspirações do Espírito naturalmente presentes na obra de Torres Queiruga para enfrentarmos os desafios da missão hodierna". A questão central que busca responder é: "como recorrer ao Espírito Santo para realizarmos a missão evangelizadora na atualidade?" A resposta se concentra na análise sobre a presença constante de Jesus Cristo na história. Para compreender o Deus amoroso que Jesus apresenta, Queiruga "apresenta uma proposta inteligível que traz arrazoadas iluminações das questões teológicas atuais".

Francisco de Aquino Júnior trata da "Historicidade do reinado de Deus, como centro da vida e missão de Jesus e de sua Igreja", uma das ênfases da teologia do século XX. Mostra como isso marca o Concílio Vaticano II e a renovação teológico-pastoral da América Latina, com sua evangelização libertadora e sua teologia da libertação, entendidas como "sua expressão mais fecunda e profunda".

Geraldo Luiz De Mori reflete sobre "Crer e interpretar: uma nova 'virada' hermenêutica da teologia?" Mostra em seu artigo como o surgimento da hermenêutica, no séc. XIX, influencia as chamadas "ciências do espírito", como a exegese e a teologia cristãs, sobretudo as pesquisas de Schleiermacher, Dilthey, Heidegger, Gadamer e Ricoeur.

Francisco das Chagas de Albuquerque apresenta o estudo sobre "Uma Política ética: contribuição do pensamento ético de I. Ellacuría", mostrando que "a relação entre Ética e Política é não só possível, mas também necessária". A política ética exige nas decisões políticas a "reta consciência": 
uma consciência que corresponde à realidade da qual ela trata e a suas exigências. Particularmente nos países empobrecidos, "uma política ética tem como critério primeiro a "opção preferencial pelos pobres", caracterizando-se como "ética da libertação".

Mariana Pfister e Glauco Barsalini enriquecem este número de Pistis \& Práxis tratando da "Teologia da Veste e os dispositivos de poder: notas sobre a relação nudez - veste". Analisam o conceito de oikonomia trinitária, verificando "a ideia de um governo divino providencial do mundo". Utilizam Giorgio Agamben e Erick Peterson para refletirem sobre "teologia da Veste e os dispositivos de poder", analisando a "necessidade que o poder tem de criar e nutrir dispositivos" para se manter, numa divisão entre ser e agir - na economia trinitária e na vida humana.

Conclui essa sessão de artigos o estudo de Solange Maria do Carmo e Eduardo César Rodrigues Calil, que escrevem sobre "Um samaritano desconcertante", analisando a parábola narrada em Lc 10,25-37. Aprofundam a Boa Nova da compaixão e da misericórdia como modus essendi et operandi do próprio Cristo, imerso na história humana. Isso implica um modo de ser discípulo/a e ser igreja hoje, como também um modo de ser teólogo/a, "evitando reduzir sua mensagem a formulações religiosas obtusas", e explicitando "a riqueza e a amplidão do Reino" com imagens significativas para hoje.

Boa leitura!

\section{Referências}

BOFF, C. Teoria do Método Teológico. Petrópolis: Vozes, 1998.

GADAMER, J. G. Verdade e Método: traços fundamentais para uma hermenêutica filosófica. Petrópolis: Vozes, 1997.

GEFFRÉ, C. Le Christianisme au risque de l'interprétation. Paris: Cerf, 1983.

KUHN, T. S. The Structure of Scientific Revolutions. Chicago: University of Chicago Press, 1962.

MONDIN, B. Introduzione alla Teologia. Milão: Massimo, 1983

FRANCISCO, Papa. Exortação apostólica Evangelii Gaudium - Sobre o anúncio do Evangelho no mundo atual. São Paulo: Paulus; Loyola, 2014. 
FRANCISCO, Papa. Carta Encíclica Laudato Si' - Sobre o cuidado da casa comum. São Paulo: Paulinas, 2015.

QUEIRUGA, A. T. Repensar a Revelação - A revelação divina na realização humana. São Paulo, Paulinas, 2010.

SEGUNDO, J. L. O Dogma que Liberta - Fé, revelação e magistério dogmático. São Paulo: Paulinas, 1991. 